\title{
Enhanced expression of monocyte tissue factor in patients with liver cirrhosis
}

\author{
M Saliola, R Lorenzet, D Ferro, S Basili, C Caroselli, A Di Santo, M Sallese, F Violi
}

Institute of Clinical Medicine I, University of Rome "La Sapienza" M Saliola

D Ferro

S Basili

C Caroselli

F Violi

Antonio Taticchi Unit for Atherosclerosis and Thrombosis

R Lorenzet

A Di Santo

Laboratory of

Molecular Biology and

Pharmacology of

Receptors, Istituto di

Ricerche

Farmacologiche Mario

Negri, S Maria

Imbaro, Italy

M Sallese

Correspondence to: Professor F Violi, Clinica

Medica, Policlinico Umberto

I, Viale del Policlinico,

00185 , Rome, Italy.

Accepted for publication 18 February 1998

\begin{abstract}
Background-Previous studies have shown that cirrhotic patients produce increased amounts of thrombin but the underlying mechanism is still unknown. Aims-To analyse the relation between the rate of thrombin generation and monocyte expression of tissue factor (TF) in cirrhosis.

Patients-Thirty three cirrhotic patients classified as having low $(n=7)$, moderate $(n=17)$, or severe $(n=9)$ liver failure according to Child-Pugh criteria.

Methods-Prothrombin fragment F1+2, monocyte TF activity and antigen, and endotoxaemia were measured in all patients. Polymerase chain reaction (PCR) analysis of TF mRNA was performed in monocytes of five cirrhotic patients.

Results-Prothrombin fragment F1+2 was higher in cirrhotic patients than in controls $(p<0.0001)$. Monocytes from cirrhotic patients had higher TF activity and antigen than those from controls $(p<0.001)$ with a progressive increase from low to severe liver failure. Monocyte expression of TF was significantly correlated with plasma levels of F1+2 (TF activity: $r=0.98, p<0.0001$; TF antigen: $r=0.95$, $\mathbf{p}<0.0001$ ) and with endotoxaemia (TF activity: $r=0.94, p<0.0001$; $T F$ antigen: $r=0.91, p<0.0001)$. PCR analysis of TF mRNA showed TF expression only in three patients with endotoxaemia (more than $15 \mathrm{pg} / \mathrm{ml}$ ).

Conclusions-Cirrhotic patients have enhanced expression of TF which could be responsible for clotting activation, suggesting that endotoxaemia might play a pivotal role.

(Gut 1998;43:428-432)
\end{abstract}

Keywords: prothrombin fragment $\mathrm{F} 1+2$; tissue factor; monocyte

Among the complex haemostatic disturbances occurring in liver cirrhosis, hyperfibrinolysis is considered one of the most frequent disorders observed in patients with the decompensated state. ${ }^{1}$ However, it is still debated whether hyperfibrinolysis is primary or secondary to clotting activation. ${ }^{2}$ Recently, we provided evidence that in patients with liver cirrhosis hyperfibrinolysis is secondary to an ongoing prothrombotic state which was documented by elevated circulating levels of the prothrombin fragment $\mathrm{F} 1+2$, a marker of in vivo thrombin generation. ${ }^{3}$ Clotting activation was particularly evident in patients with moderate to severe liver failure, suggesting a role for liver dysfunction in accelerating the thrombin generation rate.

Tissue factor (TF) is a membrane bound glycoprotein which is induced or expressed by circulating monocytes by means of specific inflammatory mediators and triggers the extrinsic pathway of the clotting system. ${ }^{45}$ Calmus and Robert ${ }^{6}$ found increased procoagulant activity in monocytes of cirrhotic patients but they did not investigate whether this was a result of enhanced expression of TF. The aim of the present study was to analyse the relation between clotting activation and monocyte expression of TF in cirrhotic patients with different degrees of liver failure.

\section{Materials and methods}

SUBJECTS

A total of 33 patients (23 males, 10 females; aged 39-72 years) with liver cirrhosis and 14 healthy volunteers ( 6 males, 8 females; aged 27-79 years) was studied. In all patients the diagnosis of cirrhosis was supported by liver needle biopsy. In patients with severe liver failure and coagulopathy, diagnosis was based on liver biopsy performed during a previous hospital stay. Patients were excluded if they had: hepatocarcinoma, diagnosed by the combination of hepatic ultrasound and/or computed tomography, and serum $\alpha$ fetoprotein; spontaneous bacterial peritonitis or other infectious diseases, diagnosed by clinical (fever and/or abdominal pain) and laboratory (ascitic and blood culture, polymorphonuclear count in ascitic fluid) indexes; or cholestatic liver disease.

All patients gave informed consent to inclusion in the study. The standard treatment consisted of spironolactone, furosemide, ethacrinic acid, albumin, and lactulose. Patients were not given non-absorbable antibiotics or any other type of antibiotic in the previous 30 days. Patients were excluded from the study if there was an immediate need for blood or plasma. Patients included in the study gave a complete clinical history with particular reference to previous bleeding; nine patients had gastrointestinal bleeding at least three months before enrolment in the study. All patients underwent a complete physical examination with the purpose of scoring liver failure. Degree of liver failure was defined as low (class A), moderate (class B), or severe (class C) according to the Child-Pugh criteria, including clinical (ascites, encephalopathy) and laboratory (albumin, bilirubin, prothrombin time) parameters. Seven $(21 \%)$ patients were assigned to class A, 17 $(51 \%)$ to class $\mathrm{B}$, and nine $(28 \%)$ to class $\mathrm{C}$. 
Among the 33 patients, 11 (33\%) had serological markers for hepatitis B virus (HBV), $14(42 \%)$ had markers for hepatitis C virus (HCV), and eight (24\%) had a history of alcoholism. This study was approved by the Internal Medicine Review Board of the Institution.

STUDY DESIGN

A cross sectional study including the measurement of monocyte TF expression, plasma levels of $\mathrm{F} 1+2$, and endotoxaemia was carried out in cirrhotic patients and controls.

In a second study TF mRNA was measured in monocytes taken from cirrhotic patients who were selected if they had normal leucocyte count and gave informed consent. This selection was necessary due the large amount (80 $\mathrm{ml}$ ) of blood required.

BLOOD COAGULATION STUDY

Between 800 and 900 am, a blood sample (nine parts) was obtained from patients and healthy volunteers; it was mixed with $3.8 \%$ sodium citrate (one part) and treated for study of the clotting system, as reported below. Patients had fasted for at least 12 hours and had not taken any drug known to interfere with coagulation or the fibrinolytic system in the previous 15 days. Citrated blood samples were immediately centrifuged at $4^{\circ} \mathrm{C}$ for 20 minutes at $2000 \mathrm{~g}$, and the supernatant was stored at $-80^{\circ} \mathrm{C}$ until use.

Plasma levels of human prothrombin fragment $\mathrm{F} 1+2$ were assayed by an enzyme immunoassay based on the sandwich principle (Enzygnost F1+2, Behringwerke, Marburg, Germany; reference value $0.6(0.2) \mathrm{nM}$, range $0.3-1.2) .^{3}$ Intra-assay and interassay coefficients of variation were $8 \%$ and $9 \%$ respectively.

\section{ENDOTOXIN ASSAY}

The measurement of endotoxaemia was performed according to a commercially chromogenic substrate test (Kabi-Diagnostica, Stockholm, Sweden) as previously described. ${ }^{3}$ Blood sampling and endotoxin assay were performed in a laminar flow bank (Biohazard VBH-48 MP Steril, Milan, Italy), and all laboratory material was sterile, showing a linear relation between endotoxin concentration and absorbance over the $0-200 \mathrm{pg} / \mathrm{ml}$ range. All sample assays were performed in duplicate. In addition, two blank values were prepared for each test sample by adding endotoxin free water instead of the same volume of diluted plasma or Limulus amoebocyte lysate (LAL) respectively. This procedure ensures that an aseptic technique has been used. The day to day coefficient of variation was $11 \%$ (reference value 4.5 (2.6) $\mathrm{pg} / \mathrm{ml})$.

\section{ISOLATION AND INCUBATION OF BLOOD}

MONONUCLEAR CELLS

Peripheral blood mononuclear cells (PBMCs) were isolated from heparinised venous blood using an aseptic technique. Platelets were removed using two step centrifugation: once at $140 \mathrm{~g}$ and twice at $100 \mathrm{~g}$ in phosphate buffered saline (PBS) at room temperature for $10 \mathrm{~min}$ utes. PBMCs were isolated by centrifugation on lymphoprep (Nyegaard, Oslo, Norway) at $1200 \mathrm{~g}$ for 20 minutes at $20^{\circ} \mathrm{C} .{ }^{6}$ Monocytes, identified by May Grunwald Giemsa staining, comprised 16-22\% (mean 19\%). Monocytes (adherent cells) were obtained by incubation of the PBMCs for 90 minutes at $37^{\circ} \mathrm{C}$ in a humidified atmosphere of $5 \% \mathrm{CO}_{2}$ in air in Petri dishes containing RPMI 1640, supplemented with $2 \mathrm{mM}$ glutamine; lymphocytes (non-adherent cells) were removed by aspiration with a Pasteur pipette and washing of the dishes with warm media. ${ }^{7}$ The purified monocyte preparation contained $85-95 \%$ monocytes. After isolation cells were washed twice in PBS and incubated at $2 \times 10^{5}$ cells $/ \mathrm{ml}$ in RPMI 1640 at $37^{\circ} \mathrm{C}, 5 \% \mathrm{CO}_{2}$ for six hours. Cultures were performed either without stimuli or in the presence of lipopolysaccharide (LPS; Escherichia coli OB11:B4, Sigma, St Louis, Missouri, USA) at a final concentration of 200 $\mathrm{pg} / \mathrm{ml}$. At the end of the incubation period, cells and media were separated by centrifugation (2000 $g$ for 15 minutes). The cells were washed with Tris- $\mathrm{NaCl}$ buffer $(0.1 \mathrm{mmol} / 1 \mathrm{NaCl}, 0.1 \%$ bovine serum albumin, $\mathrm{pH} 7.4$ ), then lysed in the same buffer by adding $15 \mathrm{mmol} / \mathrm{l} n$-octyl-Dglycopyranoside at $37^{\circ} \mathrm{C}$ for 30 minutes. ${ }^{8}$ Cell count and trypan blue exclusion were performed on cell suspensions after washing.

\section{TISSUE FACTOR ASSAY}

TF activity was determined in the cell lysate, by measuring monocyte procoagulant activity with a one stage clotting assay. In five patients TF activity was measured in PBMC lysate, within one hour of blood withdrawal. Briefly, $100 \mu \mathrm{l}$ aliquots of cell lysate were added to 100 $\mu \mathrm{l}$ of normal pooled citrated plasma; after 150 seconds' incubation at $37^{\circ} \mathrm{C}, 100 \mu \mathrm{l}$ of 0.025 $\mathrm{mM} \mathrm{CaCl}$, was added and clotting time recorded. All samples were tested in duplicate. Clotting times were converted to arbitrary $\mathrm{TF}$ units (U) $/ 2 \times 10^{5}$ monocytes using logarithmic plots of clotting time versus dilution of a standard TF solution obtained using commercial thromboplastin (Dade). Undiluted thromboplastin was assigned a value of $1000 \mathrm{TF}$ units, corresponding to a clotting time of 14 seconds. This procoagulant activity was not seen with plasma deficient in factors VII, X, or $\mathrm{V}$.

The enzyme linked immunosorbent assay (ELISA) for measuring TF antigen in cell lysate was performed using a commercial kit (Imubind Tissue factor ELISA Kit, American Diagnostica Inc., Greenwich, Connecticut). The lower detection limit is approximately 10 $\mathrm{pg} / \mathrm{ml}$. The assay recognises $\mathrm{TF}$-apo, $\mathrm{TF}$, and TF-VII complexes and is designed such that there is no interference from other coagulation factors or inhibitors of procoagulant activity.

PCR ANALYSIS OF TF MRNA

Oligonucleotides F1 (sense bp 178-198) and $\mathrm{R} 1$ (antisense bp 495-515) from the coding sequence of human TF, and GF1 (sense bp 64-86) and GR1 (antisense bp 581-603) from the coding sequence of human glyceraldehyde 
Table 1 Clinical and laboratory characteristics of patients with liver cirrhosis

\begin{tabular}{|c|c|c|c|c|c|c|c|}
\hline Variable & $\begin{array}{l}\text { Controls } \\
(n=14)\end{array}$ & $\begin{array}{l}\text { Grade A } \\
\text { cirrhosis } \\
(n=7)\end{array}$ & $\begin{array}{l}p \text { Value } \\
(A \vee B)\end{array}$ & $\begin{array}{l}\text { Grade B } \\
\text { cirrhosis } \\
(n=17)\end{array}$ & $\begin{array}{l}p \text { Value } \\
(B v C)\end{array}$ & $\begin{array}{l}\text { Grade } C \\
\text { cirrhosis } \\
(n=9)\end{array}$ & $\begin{array}{l}p \text { Value } \\
(A \cup C)\end{array}$ \\
\hline Mean (SD) age (y) & $52(16)$ & $57(11)$ & NS & $62(8)$ & NS & $59(17)$ & NS \\
\hline $\begin{array}{l}\text { No of men (\%) } \\
\text { Unstimulated TF activity (U/2 } 2 \times 10^{5} \text { monocytes) }\end{array}$ & $6(43)$ & $5(71)$ & NS & $11(65)$ & NS & $7(78)$ & NS \\
\hline $\begin{array}{l}\mathrm{H}=19.9, \mathrm{p}<0.0001 \\
\text { LPS }(200 \mathrm{pg} / \mathrm{ml}) \text { stimulated TF activity }\left(\mathrm{U} / 2 \times 10^{5}\right.\end{array}$ & $0(<1.0-9)$ & $3.0(<1.0-15)$ & NS & $11.0(<1.0-32)$ & $<0.05$ & $41(29-55)$ & $<0.05$ \\
\hline $\begin{array}{l}\text { monocytes) } \mathrm{H}=12.5, \mathrm{p}<0.002 \\
\text { Unstimulated } \mathrm{TF} \text { antigen }\left(\mathrm{pg} / 2 \times 10^{5} \text { monocytes }\right)\end{array}$ & $9(4-22)$ & $22(6-45)$ & NS & $30(13-50)$ & $<0.05$ & $42(33-64)$ & $<0.05$ \\
\hline $\begin{array}{l}\mathrm{H}=17.0, \mathrm{p}<0.001 \\
\text { LPS }(200 \mathrm{pg} / \mathrm{ml}) \text { stimulated TF antigen }\left(\mathrm{pg} / 2 \times 10^{5}\right.\end{array}$ & $11(<10-15)$ & $17(11-40.2)$ & NS & $24(10-79)$ & $<0.05$ & $80(54-142.6)$ & $<0.05$ \\
\hline monocytes) $\mathrm{H}=15.8, \mathrm{p}<0.001$ & $16(10-40)$ & $48(19.4-68.6)$ & $<0.05$ & $62(23.6-98.9)$ & $<0.05$ & $81.1(62.5-144)$ & $<0.05$ \\
\hline $\mathrm{F} 1+2(\mathrm{nM})(95 \% \mathrm{CI}) \mathrm{F}=40.7, \mathrm{p}<0.0001$ & $\begin{array}{l}0.6(0.3) \\
(0.4-0.8)\end{array}$ & $\begin{array}{l}0.9(0.3) \\
(0.7-1.2)\end{array}$ & $<0.05$ & $\begin{array}{l}1.5(0.6) \\
(1.2-1.8)\end{array}$ & $<0.05$ & $\begin{array}{l}3.4(0.7) \\
(2.8-3.9)\end{array}$ & $<0.05$ \\
\hline Endotoxaemia $(\mathrm{pg} / \mathrm{ml}) \mathrm{H}=22.6, \mathrm{p}<0.0001$ & $4.1(0-9.6)$ & $13.4(4.4-17.5)$ & $<0.05$ & $20.5(10.5-36.5)$ & $<0.05$ & $72(43-137.5)$ & $<0.05$ \\
\hline
\end{tabular}

H, Kruskal-Wallis test among Child-Pugh classes; TF, tissue factor; F, analysis of variance among Child-Pugh classes; F1+2, human prothrombin fragment F1+2.

phosphate dehydrogenase (GAPDH) were synthesised. ${ }^{9}$ To obtain the first cDNA strand 1 $\mu \mathrm{g}$ of total RNA from mononuclear leucocytes was reverse transcribed using random hexamers and Moloney murine leukaemia virus reverse transcriptase. Polymerase chain reaction (PCR) was performed with $5 \mu \mathrm{l}$ of cDNA in $10 \mathrm{mM}$ Tris- $\mathrm{HCl}(\mathrm{pH} 8.3), 50 \mathrm{mM} \mathrm{KCl}, 2$ $\mathrm{mM} \mathrm{MgCl}{ }_{2}, 0.4 \mu \mathrm{g}$ of each appropriate sense and antisense primer, $200 \mathrm{mM}$ of each dNTP, and 2.5 units of Taq polymerase. The amplification conditions were $94^{\circ} \mathrm{C}$ for one minute, $60^{\circ} \mathrm{C}$ for one minute, and $72^{\circ} \mathrm{C}$ for one minute to obtain a product of $528 \mathrm{bp}$ from GAPDH mRNA and $317 \mathrm{bp}$ from TF mRNA. The PCR was performed in the exponential phase (cycle 23 for GADPH or 32 for $\mathrm{TF}$ ), as assessed in previous experiments, in which at various cycles $(21,23,25,28,32,35)$ the PCR products were tested (data not shown). An $8 \mu \mathrm{l}$ aliquot of the reactions was analysed on $1 \%$ agarose gel stained with ethidium bromide and subsequently by Southern blotting, for a semiquantitative analysis of PCR products for TF. The relative intensity of the bands visualised by autoradiography was measured by laser densitometry.

STATISTICAL ANALYSIS

Statistical analysis was performed by $\chi^{2}$ statistics or Fisher's exact test (if $n<5)$ for independence and by appropriate analysis of variance and/or $t$ test. When necessary, log

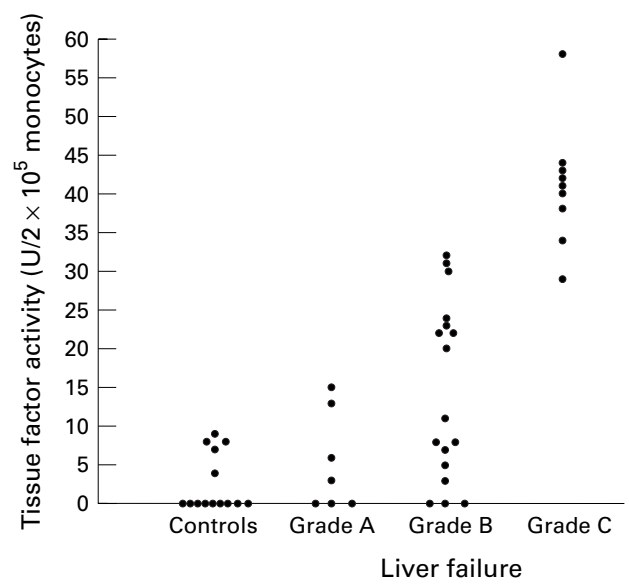

Figure 1 Tissue factor activity in unstimulated monocytes from controls and from cirrhotic patients with low (grade $A)$, moderate (grade B), and severe (grade C) liver failure. transformation was used to normalise the data, or appropriate non-parametric tests were employed. The linear regression test or Spearman rank correlation test was used to study the different correlations. Data are presented as mean (SD) and 95\% confidence intervals or as median (range). Only two tailed probabilities were used for testing statistical significance. Probability values less than 0.05 were regarded as statistically significant. ${ }^{10}$ All calculations were made with the computer program StatView II (Abacus Concepts, Berkeley, California).

\section{Results}

According to our previous work, ${ }^{3}$ patients with liver cirrhosis had an increased rate of thrombin generation compared with controls (1.9 (1.1) versus $0.6(0.2) \mathrm{nM}, \mathrm{p}<0.0001)$. $\mathrm{F} 1+2$ plasma values progressively increased from low to severe liver failure $(p<0.0001)$ (table 1).

In the absence of endotoxin, control monocytes generated low TF activity, while monocytes from cirrhotic patients had elevated levels (median (range): $<1.0 \quad(<1.0-9)$ versus 20

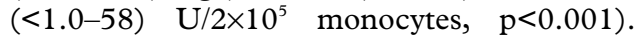
When patients with different degrees of liver failure were compared, there was a progressive increase in $\mathrm{TF}$ activity from $\mathrm{A}$ to $\mathrm{C}$ class $(p<0.0001)$ (table 1, fig 1$)$. The relation between TF activity and degree of liver failure was also observed with endotoxin stimulated

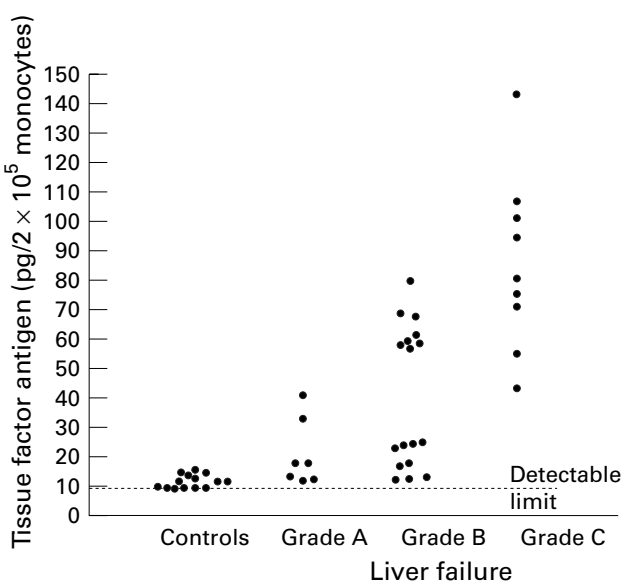

Figure 2 Tissue factor antigen in unstimulated monocytes from controls and from patients with low (grade A), moderate (grade B), and severe (grade C) liver failure. 


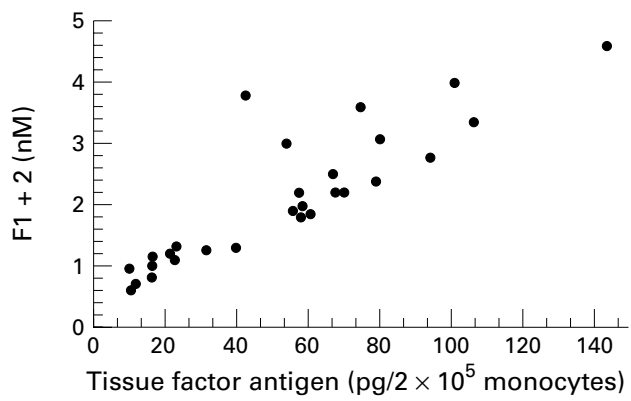

Figure 3 Correlation between tissue factor activity in unstimulated monocytes and prothrombotic fragment $F 1+2$ in cirrhotic patients.

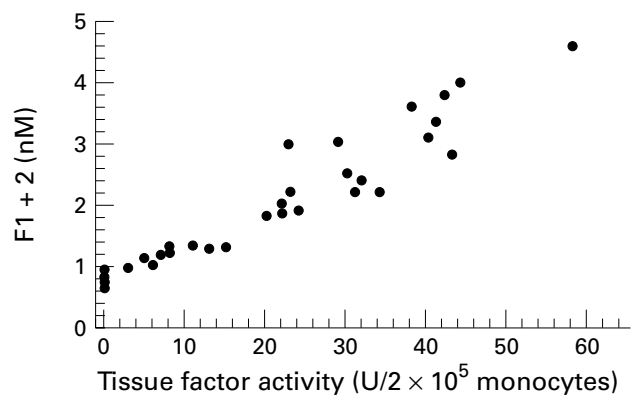

Figure 4 Correlation between tissue factor antigen in unstimulated monocytes and prothrombin fragment $\mathrm{F} 1+2$ in cirrhotic patients.

monocytes (table 1). When $\mathrm{TF}$ antigen was measured in lysed cells, TF expressed by untreated monocytes was significantly higher in cirrhotic patients than in controls (median (range): $54(10-142.6)$ versus $11.5(<10-15)$ $\mathrm{pg} / 2 \times 10^{5}$ monocytes, $\left.\mathrm{p}<0.0001\right)$. The values of $\mathrm{TF}$ antigen from unstimulated monocytes progressively increased from $\mathrm{A}$ to $\mathrm{C}$ class $(p<0.001)$ (table1, fig 2). Similar findings were observed with endotoxin stimulated monocytes (table 1$)$. Both TF activity $(r=0.98, \mathrm{p}<0.0001)$ and antigen $(r=0.95, \mathrm{p}<0.0001)$ were significantly correlated with $\mathrm{F} 1+2$ (figs 3 and 4 ).

Cirrhotic patients had higher values of endotoxaemia than controls (median (range): 20.9 (4.4-137.5) versus $4.1 \quad(0-9.6) \mathrm{pg} / \mathrm{ml}$, $\mathrm{p}<0.0001$ ) with a progressive increase from low to severe liver failure $(p<0.0001)$ (table 1$)$. A strong correlation was observed between $\mathrm{F} 1+2$ and endotoxaemia $(r=0.94, \mathrm{p}<0.0001)$; also, a strong correlation was observed between endotoxaemia and TF activity $(r=0.94$, $\mathrm{p}<0.0001)$ and antigen $(r=0.91, \mathrm{p}<0.0001)$.

Nine $(27 \%)$ of 33 patients examined had a clinical history of gastrointestinal bleeding. Similar values of $F 1+2$, endotoxaemia, and $\mathrm{TF}$ activity and antigen were observed in patients who bled and thos who did not (not shown).

To determine the steady state levels of TF mRNA, we reverse transcribed RNA from cells obtained from five different patients and

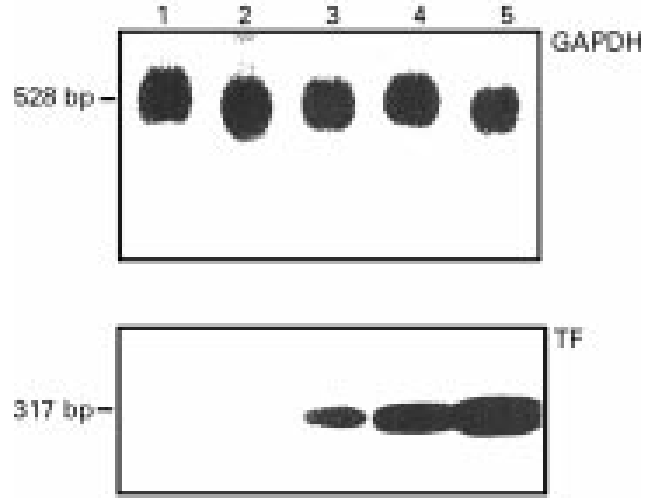

Figure 5 Tissue factor $m R N A$ levels in monocytes from cirrhotic patients. Patient numbers (1-5) correspond to those reported in table 2.

amplified it using PCR. To evaluate TF mRNA levels, a Southern blot analysis of the PCR product during amplification was performed. Table 2 shows clinical and laboratory characteristics of these patients. All patients misused alcohol; one was of A class, two of B class, and two of $C$ class. Endotoxaemia was close to the upper limits of control values in patients 1 and 2 and elevated in patients 3, 4, and 5. In these patients TF activity and antigen were measured in PBMC lysate, immediately after cell separation. In patients with almost normal endotoxaemia spontaneous TF activity was absent and the expression of TF antigen was close to the lower detection limit of the ELISA assay; patients with elevated endotoxaemia showed elevated TF activity and antigen (table 2). The PCR products for TF behaved accordingly. Those from cells obtained from patients 1 and 2 were not visible, indicating that the expression of TF mRNA is negligible (fig 5). The level of TF mRNA of cells from patients 3, 4 , and 5 was clearly evident and associated with elevated TF activity and antigen.

\section{Discussion}

Activation of the clotting system seems to be the mechanism leading to hyperfibrinolysis as the presence of systemic signs of hyperfibrinolysis (elevated plasma values of D-dimer), is closely related to an enhanced rate of thrombin generation. ${ }^{3}$ Furthermore, the enhanced rate of thrombin generation was significantly associated with tissue plasminogen activator plasma levels, further suggesting that hyperfibrinolysis is secondary to clotting activation. ${ }^{3}$

The results of the present study further reinforce the concept that in cirrhosis there is an ongoing prothrombotic state as we showed that cirrhotic patients, particularly those with moderate to severe liver failure, have an enhanced expression of TF activity and antigen. These

Table 2 Clinical and laboratory characteristics of five cirrhotic patients with low or raised endotoxaemia

\begin{tabular}{llllll}
\hline Patient no & Child-Pugh class & $F 1+2(n M)$ & Endotoxin $(p g / m l)$ & $\begin{array}{l}\text { Unstimulated TF activity } \\
\left(\text { U/2 } \times 10^{5} \text { monocytes }\right)\end{array}$ & $\begin{array}{l}\text { Tissue factor antigen } \\
\left(p g / 2 \times 10^{5} \text { monocytes }\right)\end{array}$ \\
\hline 1 & B & 0.6 & 15 & $<1.0$ & 11 \\
2 & A & 0.7 & 9.8 & $<1.0$ & 12.5 \\
3 & B & 2.2 & 43 & 34 & 70 \\
4 & C & 3.35 & 72 & 41 & 54 \\
5 & C & 3.0 & 62 & 29 & 5.2 \\
\hline
\end{tabular}


data are relevant to the understanding of the pathophysiology of clotting disturbances in cirrhosis as the overexpression of monocyte TF may represent an important stimulus for the clotting system.

Consistent with this suggestion is the strong correlation between monocyte $\mathrm{TF}$ expression and prothrombin $\mathrm{F} 1+2$ circulating levels. It is interesting to note that, compared with controls, enhanced expression of TF was found not only in lipopolysaccharide (LPS) stimulated monocytes but also in monocytes not exposed to LPS. This could indicate that in cirrhosis monocytes are activated in vivo. In accordance with this suggestion, TF mRNA could be detected in some patients with moderate to severe liver failure, suggesting that in cirrhosis there is some factor which contributes to monocyte activation. To explore this issue, we focused our attention on endotoxaemia which is elevated in cirrhosis as a consequence of impaired liver clearance ${ }^{11}$ and is an important trigger of clotting activation. ${ }^{3}$ We found a significant correlation between endotoxaemia and F1+2 plasma levels, therefore endotoxaemia may represent an important stimulus for monocyte activation in cirrhosis. ${ }^{5}$ Thus, in a range of concentrations (50-200 $\mathrm{pg} / \mathrm{ml}$ ) close to that found in cirrhosis, LPS enhances monocyte expression of $\mathrm{TF}^{12}$ Interestingly, in our cohort of cirrhotic patients with moderate to severe liver failure, endotoxaemia was on average $50 \mathrm{pg} / \mathrm{ml}$; this concentration may therefore be an adequate stimulus for monocyte activation. In accordance with this suggestion we found a significant correlation between monocyte expression of $\mathrm{TF}$ and endotoxaemia; furthermore, TF mRNA was not detected in patients with almost normal endotoxaemia while patients with endotoxaemia of more than $15 \mathrm{pg} / \mathrm{ml}$ had detectable TF mRNA. Until now, TF expression by circulating monocytes has been observed in experimental and clinical models such as septic shock and malignant disease. ${ }^{13-16}$ Cirrhosis could represent another model in which low grade endotoxaemia induces monocyte TF expression, but further study is necessary to prove definitely a cause and effect relation.

We cannot exclude the fact that other cells may contribute to activation of the clotting system as it has been shown that in cirrhosis, endotoxaemia may also induce endothelial perturbation. ${ }^{17}$ This suggestion should be investigated as activation of the clotting system could also result from endotoxin stimulation of endothelial cells, which are known to express $\mathrm{TF}$ on appropriate stimulation. ${ }^{18-20}$
In conclusion, this study shows that cirrhotic patients have enhanced monocyte TF expression, which may be responsible for systemic clotting activation, and suggests that endotoxaemia might play a pivotal role.

This work was in part supported by the Italian National Research Council (Convenzione CNR-Consorzio Mario Negri Sud).

1 Violi F, Ferro D, Basili S, et al. Hyperfibrinolysis increases the risk of gastrointestinal hemorrhage in patients with advanced cirrhosis. Hepatology 1992;15:672-6.

2 Violi F, Basili S, Ferro D, et al, and CALC group. Association between high values of D-dimer and tissueplasminogen activator activity and first gastrointestinal bleeding in cirrhotic patients. Thomb Haemost 1996;76: 177-83.

3 Violi F, Ferro D, Basili S, et al. Association between low-grade disseminated intravascular coagulation and endotoxemia in patients
ogy 1995;109:531-9.

4 Edginton TS, Mackman N, Brand K, et al. The structural biology of expression and function of tissue factor. Thromb Haemost 1991;66:67-79.

5 Nemerson Y. Tissue factor and hemostasis. Blood 1988;71: $1-8$.

6 Calmus Y, Robert A. Increased procoagulant activity in peripheral blood mononuclear cells from patients with liver cirrhosis. Thromb Res 1992;68:103-8.

7 Kornberg A, Blank M, Kaufman S, et al. Induction of tissue factor-like activity in monocytes by anti-cardiolipin antibodies. F Immunol 1994;153:1328-32.

8 Meszaros K, Aberle S, Dedrick R, et al. Monocytes tissue factor induction by lipopolysaccharide (LPS): dependence on LPS-binding protein and CD14, and inhibition by a recombinant fragment of bactericidal/permeabilityincreasing protein. Blood 1994;83:2516-25.

9 Celi A, Pellegrini G, Lorenzet R, et al. P-selectin induces the expression of tissue factor on monocytes. Proc Natl Acad Sci USA 1994;91:8767-71.

10 Armitage P, Berry G. Statistical methods in medical research, 2nd edn. Oxford: Blackwell Scientific Publications, 1990: 200-15.

$11 \mathrm{Liehr} \mathrm{H}$. Endotoxins and the pathogenesis of hepatic and gastrointestinal diseases. Adv Int Med Ped 1982;48:117-93.

12 Osterud B, Biorklid E. The production and availability of tissue thromboplastin in cellular populations of whole blood exposed to various concentrations of endotoxin. blood exposed to various concen
S Haematol 1982;29:175-84.

13 Osterud B, Flaegstad T. Increased tissue thromboplastin activity in monocytes of patients with meningococcal infection: related to an unfavourable prognosis. Thromb Haemost 1983;49:5-7.

14 Warr TA, Rao LVM, Rapaport SI. Disseminated intravascular coagulation in rabbits induced by administration of endotoxin or tissue factor. Effect of anti-tissue factor antibodies and measurement of plasma extrinsic pathway inhibitory activity. Blood 1990;75:1481-9.

15 Taylor FB Jr, Chang A, Ruf W, et al. Lethal E. coli septic shock is prevented by blocking tissue factor with monoclonal antibody. Circ Shock 1991;33:127-34.

16 Semeraro N, Colucci $M$. Tissue factor in health and disease. Thromb Haemost 1997;78:759-64.

17 Ferro D, Quintarelli C, Lattuada A, et al. High plasma levels of von Willebrand factor as a marker of endothelial perturbation in cirrhosis: relationship to endotoxemia. Hepatology 1996;23:1377-83.

18 Colucci M, Balconi G, Lorenzet R, et al. Cultured human endothelial cells generate tissue factor in response to endotoxin. F Clin Invest 1983;71:1893-6.

19 Bevilacqua MP, Pober JS, Majeau GR, et al. Recombinant tumor necrosis factor induces procoagulant activity in cultured human vascular endothelium: characterization and tured human vascular endothelium: characterization and
comparison with the actions of interleukin 1. Proc Natl comparison with the actions of
Acad Sci USA 1986;83:4533-7.

20 Moldow CF, Bach RR, Staskus K, et al. Induction of endothelial tissue factor by endotoxin and its precursors. Thromb Haemost 1993;70:702-6. 